\title{
NIGHT-TIME IN MID-FALL
}

IT is a storm-strid night, winds footing swift

Through the blind profound;

I know the happenings from their sound;

Leaves totter down still green, and spin and drift;

The tree-trunks rock to their roots, which wrench and lift

The loam where they run onward underground.

The streams are muddy and swollen; eels migrate

To a new abode;

Even cross, 'tis said, the turnpike-road;

(Men's feet have felt their crawl, home-coming late):

The westward fronts of towers are saturate,

Church-timbers crack, and witches ride abroad.

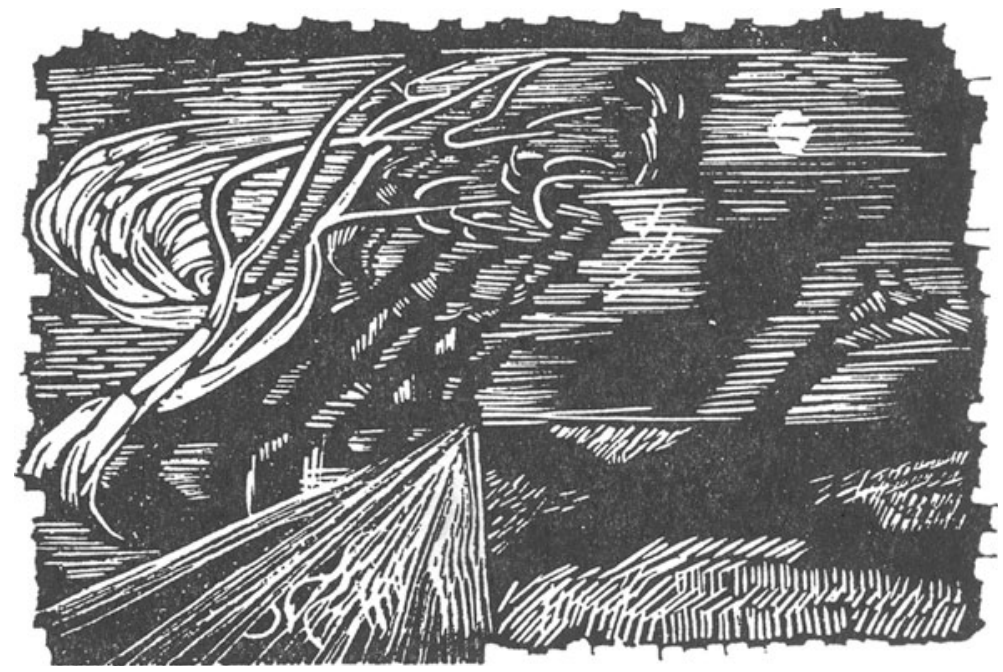

